\title{
Short communication: Effect of freezer storage time and thawing method on the recovery of Mycoplasma bovis from bovine colostrum
}

\author{
L. Gille, ${ }^{* 1}$ F. Boyen,† L. Van Driessche, ${ }^{*}$ B. Valgaeren, ${ }^{*}$ F. Haesebrouck,† P. Deprez, ${ }^{*}$ and B. Pardon* \\ *Department of Large Animal Internal Medicine, and \\ †Department of Pathology, Bacteriology and Avian Diseases, Faculty of Veterinary Medicine, Ghent University, Salisburylaan 133, \\ 9820 Merelbeke, Belgium
}

\section{ABSTRACT}

Mycoplasma bovis is an important cause of mastitis in dairy cattle, and pneumonia, arthritis, and otitis in calves. Milk and colostrum are considered important sources of infection for calves. Knowledge on the effect of on-farm freezing $\left(-18^{\circ} \mathrm{C}\right)$ and thawing methods on the recovery of $M$. bovis from colostrum samples is missing. In this study, 2 separate experiments were performed. The first experiment consisted of a longitudinal study examining the survival [as measured by $\log (10)$ reduction] of $2 \mathrm{M}$. bovis strains in frozen colostrum over $14 \mathrm{wk}$. The second experiment examined the effect of different thawing temperatures $\left(45\right.$ and $20^{\circ} \mathrm{C}$ ), thawing frequencies (once or twice), and initial colostrum titer $\left(10^{4}\right.$ or $\left.10^{6} \mathrm{cfu} / \mathrm{mL}\right)$ on $M$. bovis survival. A single freeze-thaw cycle led to an approximate 1 log reduction of $M$. bovis titer, independent of the thawing temperature. Freezing for 14 wk did not significantly further reduce the titer of bacteria compared with freezing for 2 wk. A second freeze-thaw cycle further reduced the $M$. bovis count by approximately $0.5 \log$ compared with a single freeze-thaw cycle. Thawing temperature and initial bacterial concentration did not significantly affect $M$. bovis reduction. In conclusion, storage of colostrum samples in the freezer at $-18^{\circ} \mathrm{C}$ during epidemiological studies, herd monitoring, or test and cull programs will probably have little influence on qualitative bacteriological test results for $M$. bovis. The epidemiological or clinical relevance of an approximate $1 \log$ reduction of $M$. bovis in colostrum is currently unclear.

Key words: Mycoplasma bovis, survival, freezing, colostrum

\section{Short Communication}

Mycoplasma bovis has been recognized as an important cause of untreatable mastitis in adult cattle and

Received May 8, 2017.

Accepted August 29, 2017.

${ }^{1}$ Corresponding author: Linde.Gille@Ugent.be chronic, unresponsive pneumonia in calves, frequently complicated by arthritis and otitis (Maunsell and Donovan, 2009; Maunsell et al., 2011). Annual losses due to $M$. bovis have been estimated to be above 4140 million in the United States (Rosengarten and Citti, 1999). It is generally accepted that the most important route of $M$. bovis introduction onto a farm consists of purchase of a carrier (Fox, 2012). Sperm can be infectious (Pfützner and Sachse, 1996), and recent work suggests the possibility of between herd spread through fomites or persons (Gille et al., 2016).

Known routes of transmission at individual animal level are the milking process, direct nasal contact, semen, and the consumption of infected milk (Pfützner and Sachse, 1996; Fox et al., 2005). For calves, in particular, consumption of infected milk is believed to be the primary route of infection (Walz et al., 1997; Butler et al., 2000; Maunsell and Donovan, 2009; Maunsell et al., 2012). Relatively few studies have documented the within-herd prevalence of $M$. bovis in milk samples. In a recent Swiss study, the within-herd prevalence of $M$. bovis-shedding cows was $2.4 \%(95 \% \mathrm{CI}=1.5-3.8)$ in milk by PCR assay (Aebi et al., 2015). In other studies, a within-herd prevalence between 2.6 and $43.0 \%$ has been reported (Fox, 2012).

Colostrum has been mentioned as a possible source of infection, but the prevalence of $M$. bovis in colostrum samples is currently unknown (Godden et al., 2006). Preliminary PCR testing of colostrum samples at the Belgian center for milk quality control (MCCVlaanderen, Lier, Belgium) did identify some positive samples (K. Supré, Milk Control Centre Flanders, Lier, Belgium, personal communication). The presence of $M$. bovis in colostrum is currently unaccounted for in M. bovis-preventive protocols. Indeed, the commonly recommended individual housing for $8 \mathrm{wk}$ without nose-nose contact, together with replacing cow milk by milk replacer, might have limited efficacy to reduce mycoplasma infection if $M$. bovis-positive colostrum has been given previously (Maunsell and Donovan, 2009). Colostrum samples are often stored frozen before analysis (Godden, 2008); however, it is unknown how 
freeze-thaw cycles affect recovery of $M$. bovis from these colostrum samples. Freezing of milk samples has been shown to reduce the recovery of $M$. bovis by culture (Boonyayatra et al., 2010). Considering the different composition of colostrum compared with milk (Foley and Otterby, 1978), simple extrapolation of the survival data of $M$. bovis in milk to colostrum may be incorrect (Boonyayatra et al., 2010).

The objectives of the present study were to determine the effect of the duration of the freezing period, the number of freeze-thaw cycles, and the thawing temperature on the survival of $M$. bovis in colostrum samples inoculated with 2 concentrations of $M$. bovis. Two separate experiments were conducted to achieve these objectives.

The colostrum used in experiments 1 and 2 was gamma-irradiated frozen bovine colostrum (ECI, Marloie, Belgium), guaranteeing immunoglobulin levels over 70 $\mathrm{g} / \mathrm{L}$ and a sterile product. Sterility was verified by plating the colostrum on standard blood culture, incubated at $37^{\circ} \mathrm{C}, 5 \% \mathrm{CO}_{2}$ for $24 \mathrm{~h}$ on Pleuropneumonia Like Organism (PPLO) agar (Difco, Becton Dickinson and Company, Franklin Lakes, NJ), and incubated for $1 \mathrm{wk}$ to check for mycoplasmal growth specifically. Colostrum was thawed at room temperature before inoculation with $M$. bovis.

In experiment 1 , the effect of the duration of the freezing period on survival of $M$. bovis in colostrum was evaluated. Two strains of $M$. bovis were inoculated in colostrum. At inoculation and after 1, 4, 10, and 14 wk of storage at $-18^{\circ} \mathrm{C}, 3$ colostrum samples for each strain were thawed at $20^{\circ} \mathrm{C}$ (room temperature) and serial culture was performed to determine the $M$. bovis titer.

In experiment 1, 2 strains of $M$. bovis (LG1 and LG2) were used. Strain LG1 originated from a bronchoalveolar lavage sample from a calf with pneumonia; LG2 originated from a milk sample from a cow with mastitis, arthritis, and an infected seroma (Gille et al., 2016). Mycoplasma bovis species identification was confirmed by use of real-time PCR targeting the uvrC gene of filter-cloned isolates (Rossetti et al., 2010). In preparation for this study, $200 \mu \mathrm{L}$ of a $M$. bovis strain suspended in a storage medium consisting of $75 \mathrm{~mL}$ of horse serum (Thermo Fisher Scientific, Carlsbad $\mathrm{CA}$ ) and $25 \mathrm{~mL}$ of brain heart infusion broth (BioRad, Hercules CA) supplemented with $10 \%$ (wt/vol) glucose (Merck, Darmstadt, Germany) was inoculated into $10 \mathrm{~mL}$ of modified PPLO broth (Difco). After inoculation, the broth was incubated for $5 \mathrm{~d}$ at $35^{\circ} \mathrm{C}$ and $5 \% \mathrm{CO}_{2}$, after which the PPLO broth was centrifuged at $4500 \times g$ for $30 \mathrm{~min}$ at $21^{\circ} \mathrm{C}$ to sediment the bacteria. The supernatant was discarded and the pellet was resuspended in sterile PBS. Dilution of the bacterial suspension to approximately $10^{10} \mathrm{cfu} / \mathrm{mL}$ was done by use of an optical density meter (Ultrospec III, Pharmacia Biotech, Cambridge, UK). The sample was diluted until an optical density of 0.2 absorbance units at $540 \mathrm{~nm}$ was achieved, based on specifications by Boonyayatra et al. (2010). Further dilution was done to achieve starting titers of $10^{6} \mathrm{cfu}$ of $M$. bovis $/ \mathrm{mL}$ of colostrum. The inoculated colostrum samples were stored in sterile 15-mL Falcon centrifugation tubes (Thermo Fisher Scientific, Waltham, MA) and frozen at $-18^{\circ} \mathrm{C}$. Mycoplasma bovis titer was determined immediately after complete thawing (no ice visible). One hundred microliters of colostrum was plated on PPLO agar using serial dilutions. Samples were incubated for 1 wk at $35^{\circ} \mathrm{C}$ and $5 \% \mathrm{CO}_{2}$, and colonies (with the typical fried-egg appearance) were counted with help of a microscope (10× magnification). Each sample was only plated once, but for each time point multiple samples were thawed.

To determine the effect of freezing over a 14 -wk period and the effect of $M$. bovis strain on the survival of $M$. bovis in colostrum samples, a linear mixed model with repeated measures was used (PROC MIXED). Five time points (at inoculation, after 1, 4, 10, and $14 \mathrm{wk}$ ) were included as the within-subject factors; strain type (LG1 vs. LG2) was added as a between-subject factor. The sample size (3 observations per group per time point) was based on the detection of a $1 \log$ difference between both strains, with a standard deviation of 0.4 $\log , 80 \%$ power, and $95 \%$ certainty. Mauchly's test of sphericity was used to determine equality of variances. Model validity was checked through inspection of the residuals. Bonferroni corrections were used for pairwise comparisons between the different time points. A compound symmetry repeated variance structure was used. In all models significance was set at $P<0.05$, and 0.05 $<P<0.10$ was considered a trend. All analyses were performed in SAS version 9.4 (SAS Institute Inc., Cary, $\mathrm{NC}$ ).

In the second experiment, the effect of repeated thawing (once or twice) and temperature of the first thawing process [either $20^{\circ} \mathrm{C}$ (room temperature) or $45^{\circ} \mathrm{C}$ ] on $M$. bovis recovery was determined using 2 inoculum titers $\left(10^{4}\right.$ and $10^{6} \mathrm{cfu}$ of $M$. bovis $\left./ \mathrm{mL}\right)$. The sample size required to detect a $1 \log$ reduction in $M$. bovis count between 2 storage and thawing methods, with $95 \%$ certainty and $80 \%$ power, was 18 observations per group (Win Episcope 2.0, Zaragoza, Spain).

A full factorial design was used with 4 test groups: (1) freezing for $2 \mathrm{wk}$ and a single thawing at $20^{\circ} \mathrm{C}$; (2) freezing for $2 \mathrm{wk}$ and a single thawing at $45^{\circ} \mathrm{C}$; (3) freezing for 1 wk and thawing at $45^{\circ} \mathrm{C}$, refrozen for 


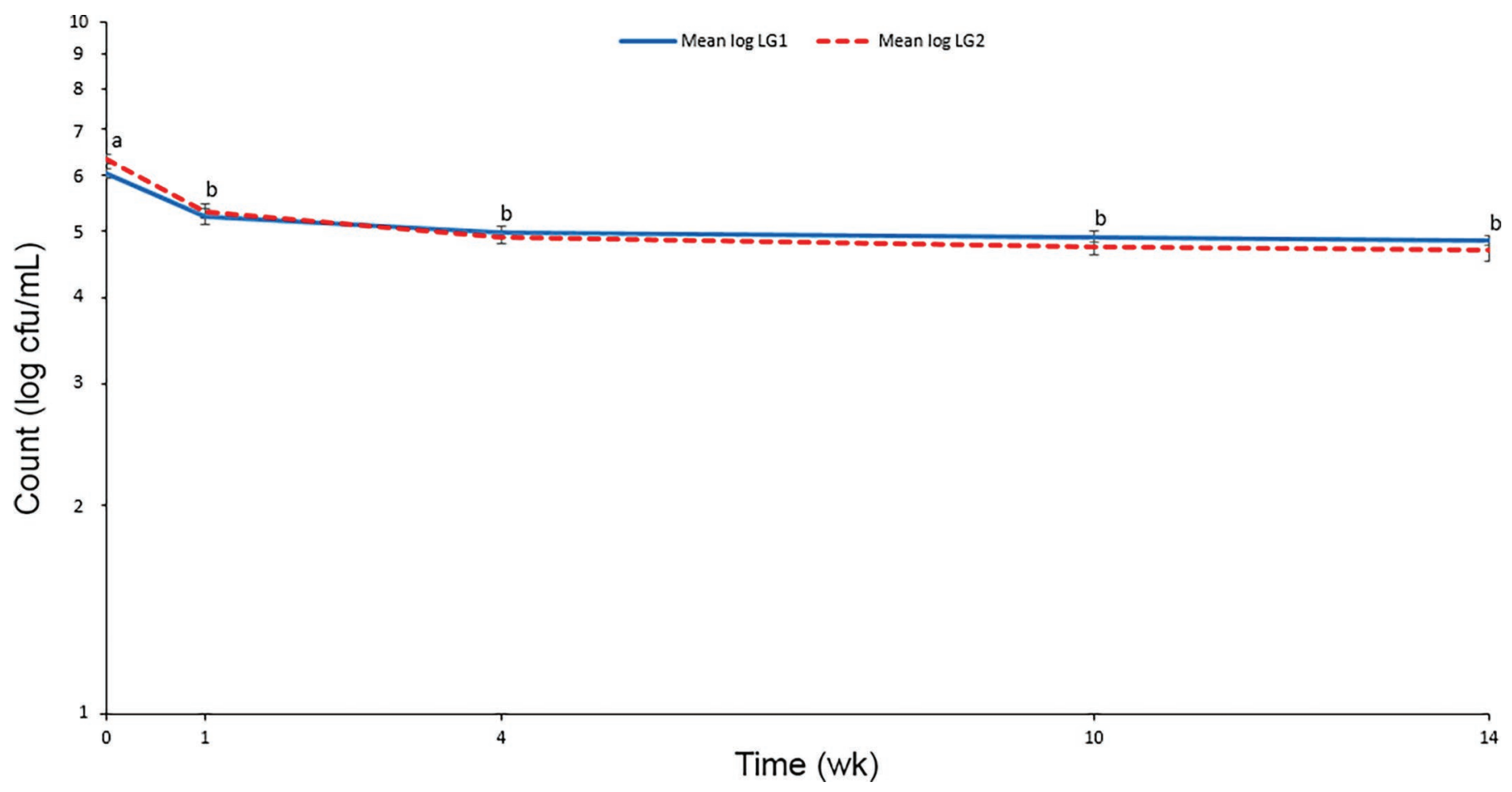

Figure 1. Mean concentration of colony-forming units per milliliter of colostrum after freezing and thawing a single time over a set time period. Time $=0=$ inoculation; time $=$ weeks of freezing. Values with different letters $(\mathrm{a}, \mathrm{b})$ are significantly different $(P<0.05)$ within subjects (time effect). Error bars represent SD. Color version available online.

$1 \mathrm{wk}$ and thawing at $20^{\circ} \mathrm{C}$; and (4) freezing for $1 \mathrm{wk}$ and thawing at $20^{\circ} \mathrm{C}$, refrozen for 1 wk and thawing at $20^{\circ} \mathrm{C}$. Sample preparation was identical to experiment 1, except that only the LG1 strain was used, in titers of $10^{4}$ and $10^{6} \mathrm{cfu}$ of $M$. bovis/mL of colostrum. The inoculated colostrum samples were split in 16 portions of $10 \mathrm{~mL}$ of colostrum, which were distributed over the 4 treatment groups. The experiment was repeated 3 times. One week after inoculation, repeated thawing groups at 20 and $45^{\circ} \mathrm{C}$ and refrozen at $-18^{\circ} \mathrm{C}$. All groups were thawed at their respective temperatures 2 wk after inoculation. Mycoplasma bovis titer was determined using the same method as in experiment 1.

A linear mixed-model (PROC MIXED) was used to determine the effects of the initial $M$. bovis concentration in colostrum $\left(10^{4}\right.$ vs. $\left.10^{6}\right)$, number of freeze-thaw cycles ( 1 vs. 2$)$, and thawing temperature $\left(20\right.$ vs $\left.45^{\circ} \mathrm{C}\right)$. The test run was added as a random effect to account for clustering of measurements within a run. A maximum likelihood estimation with Satterthwaite approximation was used. All factors were forced into the model and interactions between significant main effects were tested. Post-hoc comparisons were made using Bonferroni corrections. Model validity checking and significance definitions were as described for experiment 1 .
In experiment 1 , the effect of freezing duration on the survival of $M$. bovis in colostrum was determined. Freezing significantly reduced $M$. bovis concentration by a mean of 0.81 to $1.02 \log (\mathrm{SD}=0.13-0.15)$ for LG1 and LG2, respectively, between inoculation and 1 wk later (Figure 1). Longer freezing times did not result in further decrease in the number of $M$. bovis recovered from colostrum. No significant effect of strain was observed (Figure 1).

The effects of repeated thawing and thawing temperature tested in experiment 2 are shown in Table 1. Independent of the starting titer $\left(10^{4}\right.$ or $\left.10^{6} \mathrm{cfu} / \mathrm{mL}\right)$, freezing and thawing of $M$. bovis-infected colostrum reduced the $M$. bovis concentration by approximately 1 log compared with the initial concentration. Thawing temperature $\left(20\right.$ vs. $\left.45^{\circ} \mathrm{C}\right)$ did not have a significant effect on the survival of $M$. bovis in colostrum $(P=0.43)$. Repeated thawing of colostrum further decreased the number of $M$. bovis by approximately $0.5 \log$ compared with single thawing, regardless of the starting concentration of $M$. bovis $(P<0.05)$.

As expected, freezing and subsequent thawing of colostrum did not result in a complete elimination of $M$. bovis, similar to previous observations in milk samples (Boonyayatra et al., 2010). After a single freeze-thaw 


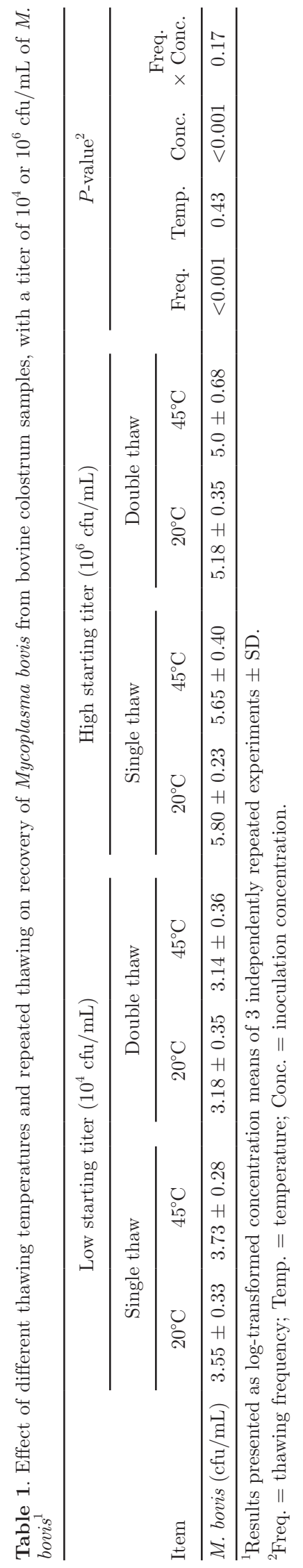

cycle, the $M$. bovis concentration was reduced by approximately $1 \mathrm{log}$, independent of the starting titer, which is comparable to the findings reported for milk samples (Boonyayatra et al., 2010). Unlike Boonyayatra et al. (2010), longer freezing intervals were tested in our study as well. This did not result in a significant further decline of $M$. bovis colony-forming units. Mycoplasma concentration in milk ranges between $10^{2}$ and $10^{8} \mathrm{cfu} / \mathrm{mL}$, with the vast majority above $10^{6} \mathrm{cfu} / \mathrm{mL}$ (Biddle et al., 2003; Cai et al., 2005). If the M. bovis concentrations in colostrum and naturally infected milk are similar, an approximate $1 \log$ reduction will result in $M$. bovis concentrations ranging between 10 and $10^{7}$ $\mathrm{cfu} / \mathrm{mL}$ of colostrum. Such M. bovis concentrations can be detected with most of the commonly used screening methods, such as PCR, ELISA, and culture (detection limit $=10 \mathrm{cfu} / \mathrm{mL}$; Biddle et al., 2003). Intermittent shedding has been described for several Mycoplasma species, so negative results should be interpreted carefully (Biddle et al., 2003).

Extension of storage time at $-18^{\circ} \mathrm{C}$ for up to $14 \mathrm{wk}$ did not further decrease the survival rate of $M$. bovis in colostrum as compared with storage for $1 \mathrm{wk}$. These results further illustrate that long-term freezing of colostrum is not a valid control strategy to prevent $M$. bovis infection of neonatal calves. Double freeze-thaw cycles resulted in a significantly larger reduction of $M$. bovis in colostrum. However, multiple freeze-thaw cycles can cause an undesirable decline in maternal antibody levels (Argüello et al., 2003) and are thus not recommended.

In conclusion, single and double freeze-thaw cycles reduced $M$. bovis concentration in colostrum by 1 to $1.5 \mathrm{log}$, respectively. Thawing temperature and initial bacterial concentration did not significantly affect the survival of $M$. bovis in colostrum. The storage of colostrum samples in the freezer at $-18^{\circ} \mathrm{C}$ during epidemiological studies, herd monitoring, or test and cull programs likely has little influence on qualitative bacteriological test results for $M$. bovis. As there are currently no indications of the minimal infective dose of $M$. bovis in colostrum, the epidemiological or clinical relevance of an approximate $1 \log$ reduction of $M$. bovis in colostrum is unclear and deserves further attention in future research. In case a lower $M$. bovis titer reduction is desired for epidemiological studies, addition of glycerol might be a valid aid, as described for milk samples by Boonyayatra et al. (2010).

\section{REFERENCES}

Aebi, M., B. H. van den Borne, A. Raemy, A. Steiner, P. Pilo, and M. Bodmer. 2015. Mycoplasma bovis infections in Swiss dairy cattle: A clinical investigation. Acta Vet. Scand. 57:10. 
Argüello, A., N. Castro, J. Capote, R. Ginés, F. Acosta, and J. L. López. 2003. Effects of refrigeration, freezing-thawing and pasteurization on IgG goat colostrum preservation. Small Rumin. Res. 48:135-139.

Biddle, M. K., L. K. Fox, and D. D. Hancock. 2003. Patterns of mycoplasma shedding in the milk of dairy cows with intramammary mycoplasma infection. J. Am. Vet. Med. Assoc. 223:1163-1166.

Boonyayatra, S., L. K. Fox, T. E. Besser, A. Sawant, and J. M. Gay. 2010. Effects of storage methods on the recovery of Mycoplasma species from milk samples. Vet. Microbiol. 144:210-213.

Butler, J. A., S. A. Sickles, C. J. Johanns, and R. F. Rosenbusch. 2000. Pasteurization of discard Mycoplasma mastitic milk used to feed calves: Thermal effects on various Mycoplasma. J. Dairy Sci. 83:2285-2288.

Cai, H. Y., P. Bell-Rogers, L. Parker, and J. F. Prescott. 2005. Development of a real-time PCR for detection of Mycoplasma bovis in bovine milk and lung samples. J. Vet. Diagn. Invest. 17:537-545.

Foley, J. A., and D. E. Otterby. 1978. Availability, storage, treatment, composition, and feeding value of surplus colostrum-Review. J. Dairy Sci. 61:1033-1060.

Fox, L. K. 2012. Mycoplasma mastitis: CAUSES, transmission, and control. Vet. Clin. North Am. Food Anim. Pract. 28:225-237.

Fox, L. K., J. H. Kirk, and A. Britten. 2005. Mycoplasma mastitis: A review of transmission and control. J. Vet. Med. B Infect. Dis. Vet. Public Health 52:153-160.

Gille, L., P. Pilo, B. R. Valgaeren, L. Van Driessche, H. Van Loo, M. Bodmer, S. Bürki, F. Boyen, F. Haesebrouck, P. Deprez, and B. Pardon. 2016. A new predilection site of Mycoplasma bovis: Postsurgical seromas in beef cattle. Vet. Microbiol. 186:67-70.

Godden, S. 2008. Colostrum management for dairy calves. Vet. Clin. North Am. Food Anim. Pract. 24:19-39.
Godden, S., S. McMartin, J. Feirtag, J. Stabel, R. Bey, S. Goyal, L. Metzger, J. Fetrow, S. Wells, and H. Chester-Jones. 2006. Heattreatment of bovine colostrum. II: Effects of heating duration on pathogen viability and immunoglobulin G. J. Dairy Sci. 89:34763483.

Maunsell, F., M. B. Brown, J. Powe, J. Ivey, M. Woolard, W. Love, and J. W. Simecka. 2012. Oral inoculation of young dairy calves with Mycoplasma bovis results in colonization of tonsils, development of otitis media and local immunity. PLoS One 7:e44523.

Maunsell, F. P., and A. Donovan. 2009. Mycoplasma bovis infections in young calves. Vet. Clin. North Am. Food Anim. Pract. 25:139-177.

Maunsell, F. P., A. R. Woolums, D. Francoz, R. F. Rosenbusch, D. L. Step, D. J. Wilson, and E. D. Janzen. 2011. Mycoplasma bovis infections in cattle. J. Vet. Intern. Med. 25:772-783.

Pfützner, H., and K. Sachse. 1996. Mycoplasma bovis as an agent of mastitis, pneumonia, arthritis and genital disorders in cattle. Rev. Sci. Tech. 15:1477-1494.

Rosengarten, R., and C. Citti. 1999. The role of ruminant mycoplasmas in systemic infections. Pages 14-17 in COST 826 Agriculture and Biotechnology: Mycoplasmas of Ruminants: Pathogenicity, Diagnostics, Epidemiology and Molecular Genetics Vol. 3. L. Stipkovits, R. Rosengarten, and J. Frey, ed. European Communities, Luxembourg City, Luxembourg.

Rossetti, B. C., J. Frey, and P. Pilo. 2010. Direct detection of Mycoplasma bovis in milk and tissue samples by real-time PCR. Mol. Cell. Probes 24:321-323.

Walz, P. H., T. P. Mullaney, J. A. Render, R. D. Walker, T. Mosser, and J. C. Baker. 1997. Otitis media in preweaned Holstein dairy calves in Michigan due to Mycoplasma bovis. J. Vet. Diagn. Invest. $9: 250-254$. 